\title{
Potensi dan Permasalahan Perikanan Budidaya di Kecamatan Caringin Kabupaten Sukabumi Provinsi Jawa Barat
}

\author{
[Potential and Problems of Aquaculture in Caringin District, Sukabumi, \\ West Java Province]
}

\author{
Nadia Ichtifa, Ganjar Wiryati, Pigoselpi Anas \\ Jurusan Penyuluhan Perikanan, Sekolah Tinggi Perikanan \\ Jalan Cikaret No. 2, Bogor Selatan, Kota Bogor 16132
}

Diterima : 10 Februari 2019; Disetujui : 12 Maret 2019

\begin{abstract}
Abstrak
Identifikasi potensi suatu wilayah merupakan salah satu langkah awal untuk menggali data dan informasi yang dilakukan secara partisipatif untuk mengetahui potensi yang dimiliki oleh suatu wilayah. Didukung dengan data yang lengkap dan valid. Metode pengambilan data diperoleh dari data primer dan data sekunder. Pengambilan sampel menggunakan metode purposive random sampling dengan menetapkan pertimbangan tertentu. Dari jumlah populasi pembudidaya terdapat 24 RTP yang tergabung pada 7 kelompok pembudidaya. Kecamatan Caringin memiliki luas wilayah 3.542,362 Hektar yang terbagi kedalam 9 desa diantaranya terdapat lahan budidaya seluas $39,5 \mathrm{Ha}$ dengan sumber pengairan dari irigasi. Tujuan penelitian adalah mengidentifikasi potensi dan permasalahan perikanan pada sistem produksi perikanan, sistem usaha perikanan dan sistem penyuluhan perikanan di Kecamatan Caringin Kabupaten Sukabumi Provinsi Jawa Barat. Hasil identifikasi menunjukan bahwa kegiatan budidaya di Kecamatan Caringin didominasi oleh pembenihan dan pendederan komoditas ikan nila serta pembenihan ikan lele. Dari teknologi yang digunakan seluruhnya masih bersifat tradisional diatandai dengan tidak adanya pemberian pakan. Produksi pembenihan ikan nila rata rata 72 liter.siklus $^{-1}$, produksi pendederan ikan nila rata-rata 163.625 ekor.siklus $^{-1}$ dan produksi pembenihan ikan lele rata rata 1.200 ekor.siklus $^{-1}$. Alur pemasaran yang digunakan pembudidaya yaitu alur pemasaran semi langsung dan tidak langsung. Kegiatan penyuluhan yang dilakukan penyuluh perikanan di Kecamatan Caringin menggunakan metode anjangsana dan pertemuan kelompok.
\end{abstract}

Kata Kunci : Kecamatan Caringin, penyuluhan, potensi perikanan

\section{Abstract}

Identifying the potential of an area is one of the first steps to explore data and information that is carried out in a participatory way to find out the potential of an area. Supported by complete and valid data. The data collection method was obtained from primary data and secondary data. Sampling uses a purposive random sampling method by setting certain considerations. From the total population of farmers there are $24 \mathrm{FHs}$ who are members of 7 groups of farmers. Caringin District has an area of 3.542,362 hectares divided into 9 villages including $39,5 \mathrm{Ha}$ of cultivated land with irrigation sources. The research objective is to identify the potential and problems of fisheries in the fisheries production system, fisheries business system and fishery extension system in Caringin District, Sukabumi Regency, West Java Province. The identification results show that the cultivation activities in Caringin District are dominated by hatchery and nursery of tilapia commodities and catfish hatchery. The technology used is entirely traditional, characterized by the absence of feeding. Production of tilapia hatchery averaged 72 liters.cycle $^{-1}$, production of tilapia nursery an average of 163.625 fish.cycle $^{-1}$ and production of catfish hatchery an average of 1.200 fish.cycle ${ }^{-1}$. The marketing channel used by farmers is semi direct and indirect marketing channels. The counseling activities carried out by fisheries counselors in Caringin District used the Anjangsana method and group meetings.

Keywords: Caringin District, counseling, fisheries potential 


\section{Penulis Korespondensi}

Nadia Ichtifa | nadiaichtifa@gmail.com

\section{PENDAHULUAN}

Dalam melaksanakan percepatan pembangunan secara nasional harus diawali adanya perencanaan yang baik (Sugiyono, 2012). Didukung dengan data yang lengkap dan data yang benar. Untuk mendapatkan kevalidan data perlu dilakukan pengambilan data dengan sistem yang sesuai kaedah-kaedah yang berlaku dengan mengidentifikasi data dan informasi yang akurat baik data potensi wilayah berupa sumber daya alam (SDA) maupun data kependudukan berupa sumber daya manusia (SDM) dan permasalahan yang dihadapi oleh pelaku utama perikanan (nelayan, pembudidaya dan pengolah perikanan) serta pelaku usaha perikanan lainnya (Arikunto, 2010).

Kecamatan Caringin Kabupaten Sukabumi, memiliki potensi budidaya ikan air tawar. Potensi tersebut ditunjang ketersediaan sumber air yang memadai. Setiap hari, Kecamatan Caringin bisa menghasilkan sekitar 5 ton benih dari komoditas ikan nila dan lele. Produksi itu diperoleh dari puluhan pembudidaya ikan air tawar yang memanfaatkan lahan sebagai kolam ikan di sekitar permukiman penduduk. Berdasarkan latar belakang tersebut, maka penulis memilih lokasi Kecamatan Caringin Kabupaten Sukabumi sebagai lokasi untuk dilaksanakan identifikasi potensi dan permasalahan perikanan yang ada di wilayah tersebut guna menggali data dan informasi sebagai acuan untuk menyusun rencana pembangunan wilayah bidang perikanan dalam rencana kerja penyuluh perikanan.

Tujuan dari penelitian ini adalah mengidentifikasi potensi dan permasalahan perikanan pada sistem produksi perikanan, sistem usaha perikanan dan sistem penyuluhan perikanan di Kecamatan Caringin Kabupaten Sukabumi Provinsi Jawa Barat.

\section{METODOLOGI}

Kegiatan pengambilan data dilaksanakan pada tanggal 1 - 30 November 2018, bertempat di Kecamatan Caringin Kabupaten Sukabumi Provinsi Jawa Barat yang difokuskan pada 3 desa potensi perikanan yaitu desa Caringin Kulon, Desa Talaga dan Desa Mekarjaya dari 9 desa yang terdapat di Kecamatan Caringin. Pengambilan sampel melalui pendekatan purposive random sampling dengan pertimbangan yang ditetapkan 
yaitu Kelompok budidaya ikan yang aktif dan sudah mendapatkan layanan penyuluhan dan usaha budidaya perikanan menjadi usaha pokok dan bukan menjdi pekerjaan sampingan serta kelompok budidaya ikan yang mengembangkan komoditas potensial. Berdasarkan pertimbangan tersebut didapatkan 106 RTP yang kemudian di hitung menggunakan rumus slovin didapatkan 24 orang responden.

Teknik Pengambilan data dan informasi yang dikumpulkan menggunakan alat bantu kuisioner yang terbagi menjadi 3 jenis kuisioner yang dibacakan kepada responden tiga jenis kuisioner tesebut yaitu kuisioner mengenai sumber daya alam, sumber daya manusia, sistem penyuluhan perikanan dan sistem usaha perikanan di Kecamatan Caringin, Kabupaten Sukabumi untuk menggali data dan informasi dalam penelitian. Pengolahan data dilakukan setelah semua data terkumpul kemudian di analisis menggunakan statistic deskriptif. Statistik deskriptif untuk menganalisis data dengan cara mendeskripsikan atau menggambarkan data yang telah terkumpul sebagaimana adanya tanpa bermaksud membuat kesimpulan yang berlaku untuk umum dan generalisasi (Sugiyono, 2015).

Analisis masalah yang digunakan yaitu analisis SWOT. Penggunaan analisis SWOT untuk menganalisa data dan informasi tentang faktor internal yang terdiri atas Kekuatan (strengths) dan Kelemahan (weaknesses) dan faktor eksternal terdiri atas Peluang (opportunities) dan Ancaman (threats), kemudian memformulasikan tindakan runtut untuk pemecahan masalah yang dihadapi (Rangkuti, 2008).

\section{HASIL DAN PEMBAHASAN \\ Potensi Sumber Daya Alam}

Berdasarkan data Kecamatan Caringin dalam angka tahun 2017, Kecamatan Caringin memiliki luas wilayah 3.542, 362 Hektar yang terbagi atas lahan pekarangan 295,587 $\mathrm{Ha}$, kolam 39,500 Ha, sawah 2.622,915 Ha, kebun 584,360 Ha. Kecamatan Caringin terdiri dari 9 desa. Desa terluas adalah Desa Caringin Kulon sebesar 845,5 Hektar. Desa paling kecil adalah Desa Talaga seluas $221 \mathrm{Ha}$ yang terletak antara $7^{0} 45,5^{\prime}$ Lintang Selatan dan $109^{037}, 0$ ' Bujur Timur. Yang mempunyai batasan wilayah sebagai berikut :

- Sebelah Utara Gunung Pangrango/Gunung Gede

- Sebelah Selatan Kecamatan Cicantayan

- Sebelah Barat Kecamatan Nagrak dan Kecamatan Cibadak

- Sebelah Timur Kecamatan Kadudampit dan Kecamatan Cisaat 


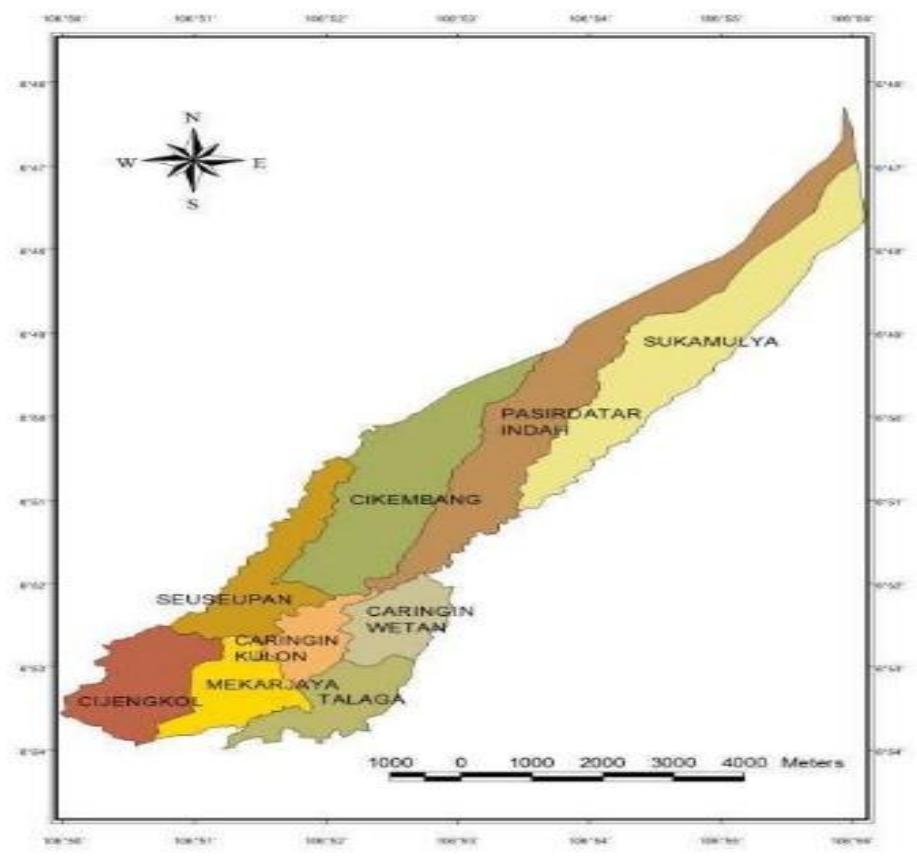

Gambar 1. Peta Kecamatan Caringin Sumber : Kecamatan Caringin Dalam Angka 2017

Tabel 1. Luas Wilayah Kecamatan Caringin

\begin{tabular}{llccc}
\hline \multirow{2}{*}{ No } & \multicolumn{1}{c}{ Desa } & \multicolumn{2}{c}{ Klasifikasi Tanah } & \multirow{2}{*}{ Jumlah (Ha) } \\
\cline { 3 - 4 } & & Sawah(Ha) & Darat(Ha) & \\
\hline 1 & Desa Caringin Kulon & 231,12 & 56,180 & 287,3 \\
2 & Desa Caringin Wetan & 102,00 & 161,300 & 263,3 \\
3 & Desa Mekarjaya & 106,00 & 115,000 & 221 \\
4 & Desa Talaga & 621,48 & 224,020 & 845,5 \\
5 & Desa Cijengkol & 150,00 & 88,900 & 238,9 \\
6 & Desa Cikembang & 351,77 & 186,030 & 537,8 \\
7 & Desa Seuseupan & 327,31 & 249,990 & 577,3 \\
8 & Desa Sukamulya & 508,269 & 292,031 & 800,3 \\
9 & Desa Pasirdatar Indah & 224,966 & 117,234 & 342,2 \\
\hline Jumlah & $\mathbf{2 6 2 2 , 9 1 5}$ & $\mathbf{1 4 9 0 , 6 8 5}$ & $\mathbf{4 0 9 6 , 6}$ \\
\hline
\end{tabular}

Sumber : BPS 2017

Kecamatan Caringin seluas 3.542,362 $\mathrm{Ha}$, sebagian jumlah lahan baik lahan sawah maupun lahan kering tersebut dapat dimanfaatkan untuk budidaya perikanan. Sumber air yang digunakan pembudidaya berasal dari irigasi dengan lebar saluran 3 meter. Komoditas yang dibudidayakan yaitu pembenihan nila, lele dan koi. 
Pembagian luas lahan yang digunakan untuk budidaya di setiap desa dapat dilihat pada Gambar 2.

Luas wilayah untuk perikanan budidaya yaitu 39,500 Ha. Berdasarkan tabel 1 diatas dapat dilihat bahwa dari 9 desa yang terdapat di Kecamatan Caringin hanya 7 desa yang memiliki lahan perikanan yaitu Desa Caringin Wetan, Desa Caringin Kulon, Desa Mekarjaya, Desa Seuseupan, Desa Talaga, Desa Cijengkol dan Desa Cikembang. Sedangkan 2 desa lainnya yaitu Desa Sukamulya dan Desa

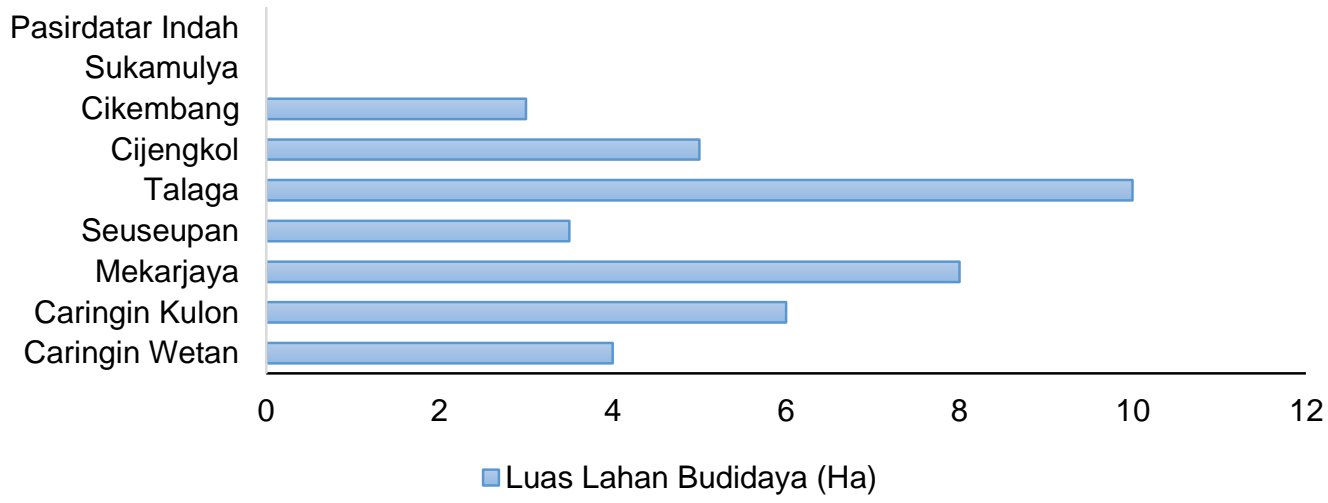

Gambar 2. Luas Lahan budidaya di Kecamatan Caringin Sumber : BP3K Caringin

Tabel 2. Curah Hujan di Kecamatan Caringin

\begin{tabular}{llcc}
\hline No & \multicolumn{1}{c}{ Bulan } & Curah Hujan $(\mathbf{m m})$ & Hari Hujan (Hari) \\
\hline 1 & Januari & 292 & 13 \\
2 & Februari & 351,5 & 15 \\
3 & Maret & 239 & 10 \\
4 & April & 233 & 13 \\
5 & Mei & 213 & 10 \\
6 & Juni & 401 & 11 \\
7 & Juli & 49 & 3 \\
8 & Agustus & 98 & 2 \\
9 & September & 357,5 & 13 \\
10 & Oktober & 565 & 18 \\
11 & November & 484 & 22 \\
12 & Desember & 394 & 20 \\
\hline \multicolumn{2}{l}{ Rata-rata } & $\mathbf{3 0 6 , 4}$ & $\mathbf{1 2}$
\end{tabular}

Sumber : BPS 2017 


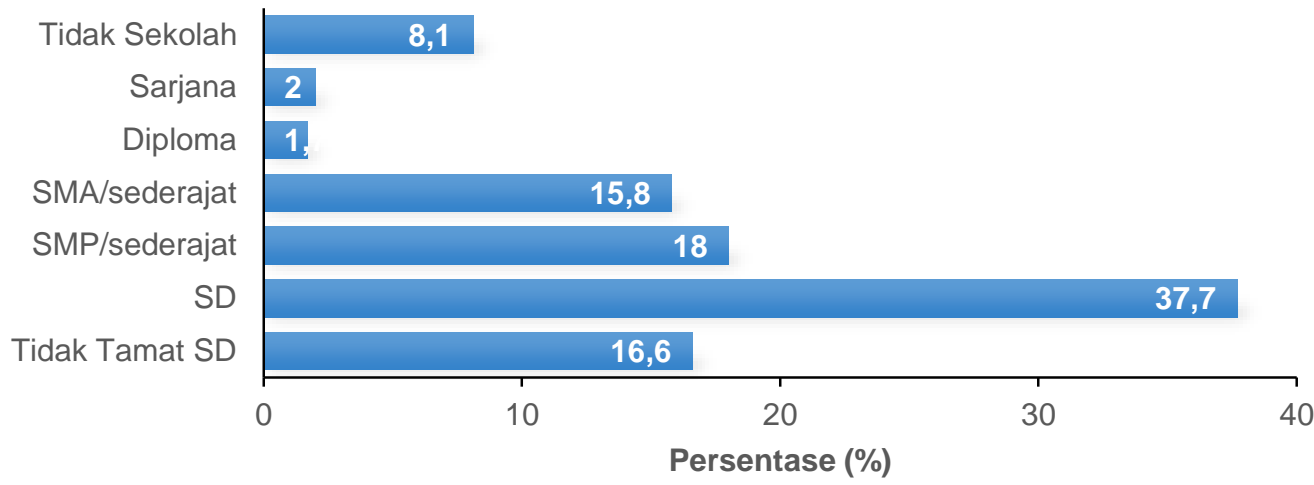

Gambar 3. Jumlah penduduk berdasarkan tingkat pendidikan

Sumber Data: Monografi Kecamatan Caringin 2018

Pasirdatar Indah di dominasi kegiatan pertanian karena didesa tersebut adalah wilayah pegunungan.

Kondisi topografis Kecamatan Caringin bergelombang dengan kemiringin $15^{\circ}$ hal ini dikarenakan Kecamatan Caringin berada pada hamparan kaki Gunung Pangrango dengan ketinggian $500 \mathrm{~s} / \mathrm{d} 1.200 \mathrm{~m}$ diatas permukaan laut (DPL). Hal ini pula yang menyebabkan suhu udara relatif dingin dengan tingkat kesuburan tanah yang cukup tinggi. Data curah hujan dapat dilihat pada Tabel 2.

Secara umum pelaku perikanan akan melakukan kegiatannya pada saat stok air melimpah. Artinya menurut tabel tersebut diartikan pula bahwa dengan kondisi curah hujan yang tertera pada tabel 2, stok air khususnya di Kecamatan Caringin cukup tersedia sepanjang tahun sehingga seharusnya usaha perikanan dapat berjalan terus menerus.

\section{Potensi Sumber Daya Manusia}

Jumlah penduduk Kecamatan Caringin berdasarkan laporan sampai dengan bulan Desember 2017 adalah 48.578 jiwa. Terdiri dari laki-laki sebanyak 25.196 jiwa dan perempuan sebanyak 23.382 jiwa. Jumlah penduduk berdasarkan tingkat pendidikan di Kecamatan Caringin dapat dilihat pada Gambar 3.

Dari penduduk Kecamatan Caringin yang ada, jumlah pendudukk usia produktif (umur 15-64 tahun) adalah 29.720 orang. Menurut UU No. 13 Tahun 2003 tentang Ketenagakerjaan, usia produktif maksudnya usia seseorang yang masih mampu menjalankan aktifitas kerja / berproduksi secara maksimal atau tanpa ada hambatan yang berarti. Dari Gambar 3 tersebut dapat dilihat bahwa semua desa di Kecamatan Caringin mempunyai jumlah tenaga kerja produktif yang cukup banyak. Ini artinya 
- Usia Produktif (Jiwa) —Usia Tidak Produktif (jiwa)

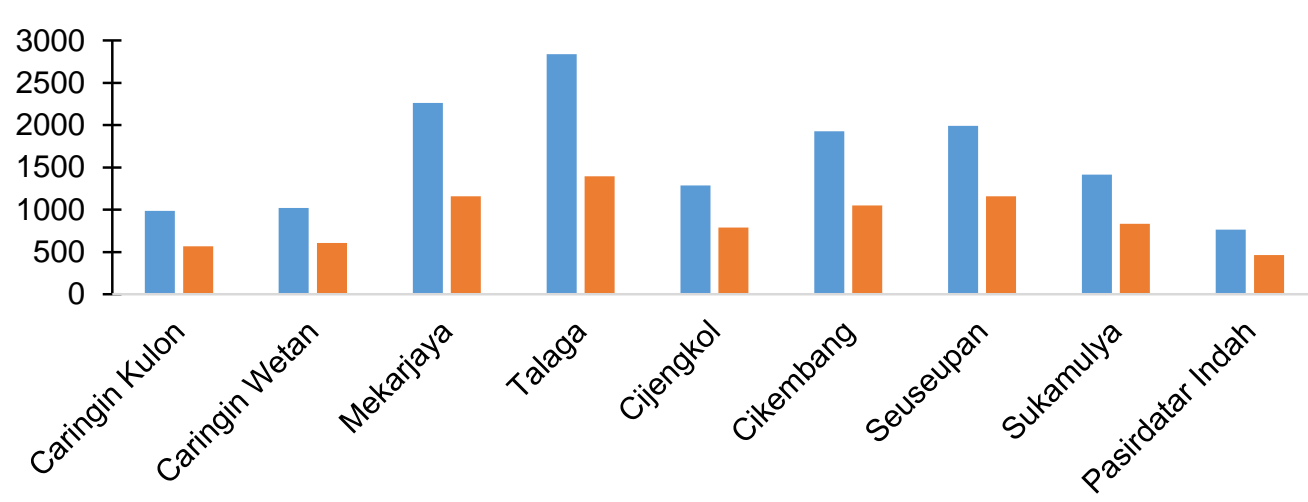

Gambar 4. Jumlah penduduk berdasarkan usia

Sumber data: Kecamatan Caringin Dalam Angka, 2017

Tabel 6. Kelompok Perikanan di Kecamatan Caringin

\begin{tabular}{lllll}
\hline No. & \multicolumn{1}{c}{ Desa } & \multicolumn{1}{c}{$\begin{array}{c}\text { Nama } \\
\text { Kelompok }\end{array}$} & \multicolumn{1}{c}{ Tahun Berdiri } & \multicolumn{1}{c}{ Keterangan } \\
\hline 1 & $\begin{array}{l}\text { Caringin } \\
\text { Kulon }\end{array}$ & Harapan Maju & 2009 & Aktif \\
\cline { 3 - 5 } 2 & \multirow{2}{*}{ Mekarjaya } & Mitra Cai & 2009 & Aktif \\
& & Anting Mas & 2018 & Aktif \\
\cline { 3 - 5 } & Nila Mekar & 2008 & Aktif \\
3 & Talaga & Berkah Mandiri & 2011 & Aktif \\
& & Anugrah Tani & 2009 & Aktif \\
& & Talaga Mandiri & 2012 & Aktif \\
\cline { 3 - 5 } & & Caringin & 2011 & Tidak Aktif \\
\multirow{3}{*}{4} & Cijengkol & Mandiri & Tidak Aktif \\
\hline
\end{tabular}

Sumber : Data Sekunder 2017

suatu usaha seharusnya dapat berjalan dan dikerjakan di tiap desa di Caringin tidak terkecuali sektor perikanan. Jumlah penduduk berdasarkan usia dapat dilihat pada Gambar 4.

Tingkat pendidikan di Kecamatan Caringin rendah, hal itu ditunjukan dengan persentase tertinggi di tingkat SD yaitu 37,7 \%. Menurut Samsuni, (2017) Pendidikan menentukan tingkat pemahaman, daya pikir dan karakter seseorang. Orang dengan pendidikan yang relative rendah membutuhkan arahan dan bimbingan intensif dalam melakukan sesuatu. Pada tabel tersebut dan dikaitkan dengan kegiatan perikanan 
maka di Kecamatan Caringin dalam menerapkan program atau rencana kegiatan harus menyertakan pendamping. Dalam hal ini keberadaan seorang penyuluh merupakan suatu hal yang sangat diperlukan untuk mendampingi, mengarahkan dan membimbing pelaku usaha perikanan dalam menjalankan usahanya.

Berdasarkan hasil wawancara dari penyuluh perikanan dan observasi lapangan, maka di dapatkan data jumlah kelompok perikanan yang berada di Kecamatan Caringin sebanyak 9 kelompok, yang seluruhnya memiliki kelas pemula dengan pengalaman yang lama yaitu rata- rata mencapai 10 tahun. pada bidang usaha budidaya tersebut. kelompok tersebut dapat dilihat pada Tabel 6.

Kelompok budidaya perikanan di Kecamatan Caringin terdapat 9 kelompok, 7 kelompok masih aktif namun 2 kelompok lainnya sudah tidak aktif berproduksi.

\section{Sistem Produksi Perikanan}

Input Produksi

Berdasarkan hasil wawancara dengan pembudidaya ikan nila bahwa usaha pembenihan ikan Nila menggunakan induk ikan yang sudah matang gonad, kolam, sumur sebagai sumber air dan pakan. Pakan untuk induk yaitu menggunakan pellet. Induk ikan nila didapatkan dari BBAT Sukabumi, Cianjur dan Parung Bogor dengan harga bervariasi mulai dari Rp. 4.000.000-Rp. 4.500.000. paket $^{-1}$. Berdasarkan hasil wawancara di dapatkan informasi bahwa satu paket indukan nila berisi 100 jantan dan 300 betina. Menurut Khairuman dan Amri, (2003) pada saat proses pembenihan, indukan nila dengan bobot $250 \mathrm{~g}$ dapat menghasilkan telur 500-1000 butir telur yang akan menetas menjadi larva sebanyak 200-400 ekor. Sarana dan prasarana selalu tersedia setiap saat.

\section{Proses Produksi}

Pemilihan lokasi yaitu di lahan di tengah penduduk, jenis kolam yang digunakan adalah kolam tanah untuk budidaya ikan nila dan kolam terpal untuk budidaya ikan lele. Sumber air yang digunakan berasal dari air irigasi. Air tersebut masuk ke kolam budidaya hanya mengandalkan kemiringan tanah dan gravitasi bumi. kolam pembenihan di gunakan rata-rata dengan luas $500 \mathrm{~m}^{2}$ dengan kontruksi kolam tanah. Menurut Murachman dan Soemarno, (2010), bahwa budidaya sistem tradisional memiliki tingkat kontrol rendah (lingkungan, nutrisi, predator dan penyakit). Sedangkan untuk kolam pembenihan lele rata- rata dengan luas $30 \mathrm{~m}^{2}$. persiapan kolam dimulai dari pengeringan, pemupukan kemudian 
pengisian air (Mahyuddin, 2010). Induk ikan nila di datangkan dari BBAT Sukabumi, Cianjur atau Parung Bogor. yang diangkut dengan sistem tertutup. Sedangkan untuk induk lele di dapatkan dari Parung maupun Cianjur. Sebelum induk ikan di tebar ke dalam kolam dilakukan aklimatisasi yang membuat induk ikan dapat beradaptasi dengan lingkungan baru.

Menurut (Mahyuddin, 2010), pemijahan ikan nila dilakukan secara massal dengan perbandingan 1:3 berdasarkan jumlah ekor ikan. Pemindahan larva ikan nila dilakukan setelah larva berumur 5-7 hari. sedangkan untuk ikan lele setelah induk memijah, ijuk langsung di pindahkan ke kolam penetasan. pakan yang diberikan pada larva ikan nila yaitu pitik sedangkan pakan ikan lele yaitu cacing sutera selam 16 hari. Pemanenan ikan nila pada umur 1-2 bulan atau ukuran ikan mencapai 2-3 $\mathrm{cm}$, 3-5 cm, dan 8-10 cm. sedangkan untuk ikan lele benih yang dipanen dengan ukuran 5-7 cm.

\section{Output Produksi}

Pemanfaatan Lahan

Berdasarkan data primer yang telah diolah didapatkan tingkat pemanfaatan lahan untuk budidaya oleh responden berada di posisi 0,72 yang bermakna lahan yang di gunakan oleh pembudidaya ikan di Kecamatan
Caringin sudah di manfaatkan secara maksimal.

Produksi dan Produktivitas

Produksi larva nila yang ada pada beberapa kelompok di Kecamatan Caringin yaitu rata-rata 571 larva per ekor induk. SR rata-rata kelompok di Kecamatan Caringin yaitu rata-rata $61 \%$. Produksi benih ikan lele menghasilkan 30.000-50.000 telur pada 1 ekor induk betina dengan bobot sekitar $1 \mathrm{~kg}$. Larva yang dikeluarkan akan menghasilkan larva 20.000-30.000 ekor, dengan demikian didapatkan HR (Hatcing Rate) atau sintasan $67 \%$.

\section{Sistem Usaha Perikanan}

Berdasarkan hasil identifikasi maka di dapatkan informasi bahwa modal yang digunakan untuk kegiatan usaha budidaya yaitu dari milik pribadi pembudidaya itu sendiri, sedangkan untuk tenaga kerja yang membantu proses budidaya sekitar 2 hingga 3 orang, tenaga kerja tersebut sebagaian besar bekerja secara tidak tetap atau sambilan yang hanya bekerja pada saat panen atau pada saat tebar saja dalam satu periode yaitu 3 bulan.

Menurut Mursyid, (2009) pasar adalah suatu koondisi dimana penjual dan pembeli saling berinteraksi. 
Tabel 7. Analisis usaha responden

\begin{tabular}{rlrr}
\hline No & \multicolumn{1}{c}{ Keterangan } & $\begin{array}{c}\text { Pendederan ikan } \\
\text { nila }\end{array}$ & $\begin{array}{c}\text { Pembenihan ikan } \\
\text { lele }\end{array}$ \\
\hline 1 & Biaya Investasi & Rp. 60.335 .000 & Rp. 11.260 .000 \\
2 & Biaya penyusutan.bulan ${ }^{-1}$ & Rp. 13.900 & Rp. 422.200 \\
3 & Biaya Penyusutan.siklus $^{-1}$ & Rp. 41.700 & Rp. 1.055 .600 \\
4 & Biaya Tetap.siklus $^{-1}$ & Rp. 93.700 & Rp. 1.155 .600 \\
5 & Biaya variabel.siklus ${ }^{-1}$ & Rp. 10.860 .500 & Rp. 4.475 .000 \\
6 & Harga Jual.ekor $^{-1}$ & Rp. 200 & Rp. 200 \\
7 & Total Biaya Produksi.siklus ${ }^{-1}$ & Rp. 10.954 .200 & Rp. 5.630 .600 \\
8 & Pendapatan & Rp. 15.500 .000 & Rp. 18.000 .000 \\
9 & Keuntungan.siklus ${ }^{-1}$ & Rp. 4.545 .800 & Rp. 12.369 .400 \\
10 & BEP(Unit) & 54.771 ekor & 28.153 ekor \\
11 & BEP (Harga) ekor $^{-1}$ & Rp. 141 & Rp. 63 \\
12 & ROI & $41 \%$ & $219 \%$ \\
13 & R/C ratio & 1,4 & 3,0 \\
14 & PP & 13 siklus & 1 siklus \\
\hline
\end{tabular}

Berdasarkan hasil wawancara, alur pemasaran di Kecamatan Caringin menggunkan pemasaran semi langsung dan pemasaran tidak langsung. Pemasaran semi langsung yaitu produsen menyalurkan hasil produksinya ke tangan pedagang eceran (Firdaus, 2011). Sedangkan menurut Laksana, (2008), pemasaran semi langsung yaitu orang yang menghasilkan produk langsung menyalurkan hasil produksnya ke pedagang yang nantinya akan disalurkan kembali. Pemasaran tidak langsung yaitu dipengaruhi jarak produsen ke konsumen, semakin jauh jarak konsumen maka akan semakin panjang jalur tataniaga (Suliyanto, 2011).

\section{Layanan pendukung}

Berdasarkan hasil identifikasi dan observasi lapangan menunjukan bahwa toko sarana dan prasarana tersedia di wilayah kecamatan. Di Kecamatan Caringin terdapat Lembaga penyuluhan yang bergabung dengan UPTD Pasar Cibaraja di Kecamatan Cisaat. Lembaga perbankan terdapat 2 unit yaitu BRI, dan BNI. berdasarkan informasi yang didapatkan dari penyuluh bahwa pembudidaya di Kecamatan Caringin hanya $10 \%$ yang meminjam modal ke bank tersebut. Akses jalan di Kecamatan Caringin berupa jalan beraspal (cor) yang cukup baik dan dapat dilalui kendaraan baik mobil maupun sepeda motor. 
Tabel 8. IFAS (Internal Factor Analysis System) Potensi Wilayah Perikanan No. IFAS

Bobot (B)

Rating

(R)

$\mathbf{B} \times \mathbf{R}$

\section{Kekuatan (Strengths/S)}

\begin{tabular}{llll}
\hline 1. Minat pengembangan teknologi ada & 0,20 & 3 & 0,60 \\
2. Lahan milik Pribadi & 0,05 & 2 & 0,10 \\
3. Pengalaman usaha cukup lama & 0,10 & 2 & 0,20 \\
$4 \quad$ Tenaga kerja tersedia & 0,05 & 2 & 0,10 \\
\hline Jumlah & & & $\mathbf{1 , 0 0}$ \\
\hline Kelemahan (Weaknesses/W) & & & \\
\hline $\begin{array}{l}\text { 1. Sistem teknologi budidaya masih } \\
\text { tradisional }\end{array}$ & 0,15 & 3 & 0,45 \\
$\begin{array}{l}\text { Kebutuhan pakan tidak terpenuhi } \\
\text { 3. Pengetahuan SDM rendah }\end{array}$ & 0,20 & 1 & 0,20 \\
4. Fungsi Kelembagaan belum berjalan & 0,10 & 2 & 0,20 \\
$\quad$ baik & 0,15 & 2 & 0,30 \\
\hline Jumlah & & & $\mathbf{1 , 3 5}$ \\
\hline Jumlah A + B & $\mathbf{1 , 0 0}$ & & $\mathbf{2 , 3 5}$ \\
\hline
\end{tabular}

Tabel 9. EFAS (External Factor Analysis System) Potensi Wilayah Perikanan

\begin{tabular}{|c|c|c|c|c|}
\hline No & EFAS & Bobot (B) & Rating (R) & $\mathbf{B} \times \mathbf{R}$ \\
\hline \multicolumn{5}{|c|}{ Peluang (Opportunities/O) } \\
\hline 1. & Pasar tersedia & 0,25 & 4 & 1,00 \\
\hline 2 & Dukungan Pemerintah ada & 0,15 & 3 & 0,45 \\
\hline 3 & Layanan pendukung tersedia & 0,20 & 3 & 0,60 \\
\hline Jun & & 0,60 & & 2,05 \\
\hline \multicolumn{5}{|c|}{ Ancaman (Threats/T) } \\
\hline 1. & Fluktuasi cuaca & 0,15 & 3 & 0,45 \\
\hline 2. & Harga jual ikan tidak stabil & 0,15 & 3 & 0,45 \\
\hline 3. & Harga Pakan mahal & 0,20 & 3 & 0,60 \\
\hline \multicolumn{2}{|c|}{ Jumlah } & 0,40 & & 1,50 \\
\hline \multicolumn{2}{|c|}{ Jumlah A + B } & 1,00 & & 3,55 \\
\hline
\end{tabular}


Analisa Usaha

Analisis usaja budidaya ikan di Kecamatn Caringin dapat dilihat di tabel 7.

\section{Analisis Masalah}

Analisis masalah disajikan pada tabel 8 dan tabel 9. Menurut Nisak, (2013) perhitungan faktor internal dan faktor eksternal didapatkan hasil perhitungan skor dari masing - masing strategi yaitu :

1. $S T: 1,00+1,50=2,50$

2. $S O: 1,00+2,05=3,05$

3. WO: $1,35+2,05=3,40$

4. WT : $1,35+1,50=2,85$

Berdasarkan hasil perhitungan tersebut, nilai tertinggi adalah $\mathrm{W}-\mathrm{O}$ yaitu Weaknessess merupakan kelemahan dan Opportunities merupakan peluang sehingga menggunakan analisis SWOT maka pendekatan $\mathrm{W}-\mathrm{O}$ dengan nilai 3,40 yaitu bagaimana memanfaatkan peluang untuk mengurangi kelemahan yang ada. Matriks SWOT dapat dilihat pada Tabel 10.

\section{Permasalahan}

- Kurangnya minat membentuk kelompok, kurangnya kerja sama antar anggota kelompok dan kerja sama antar kelompok

- Susahnya mengakses permodalan dalam pengembangan usaha kepada lembaga keuangan setempat.

- Kurangnya tenaga penyuluh yang ada di Kecamatan Caringin sehingga intensitas pertemuan antara pelaku utama dan penyuluh sangat kurang.

- Pembudidaya berkeyakinan bahwa pupuk organik seperti kotoran ayam dan sekam padi dapat dijadikan pakan pokok.

\section{Sistem Penyuluhan Perikanan}

Kelembagaan penyuluhan perikanan berada di Dinas Kelautan dan Perikanan Kabupaten Sukabumi. Dinas Kelautan dan Perikanan Kabupaten Sukabumi menjadi salah satu bagian PUSLATLUH (Pusat Pelatihan dan Penyuluhan) pada wilayah kerja UPT (Unit Pelayanan Teknis) BPPP Cisaat. Hal ini mengacu pada isi dari UU No.23 Tahun 2014 tentang Pemerintah Daerah mengenai pengambil alihan penyelenggaraan penyuluhan dengan unit kerja yang mengurusi bidang tersebut. Ketenagaan penyuluh di Kecamatan Caringin terdapat 2 orang tenaga penyuluh D4 PNS dari Dinas Kelautan dan Perikanan Kabupaten Sukabumi, yaitu Abdul Hamid, S.Pi dan tenaga penyuluh perikanan bantu yaitu Sri Mulyaningsih, A.Md. Berdasarkan UU No. 38 Tahun 2013 tentang kebijakan dan strategi penyuluhan perikanan 
Tabel 10. Matriks SWOT

\begin{tabular}{|c|c|c|}
\hline EFAS & $\begin{array}{l}\text { Kekuatan (S) } \\
\text { Minat Pengambangan } \\
\text { teknologi ada } \\
\text { Kepemilikan lahan pribadi } \\
\text { Pengalaman usaha cukup } \\
\text { lama } \\
\text { Tenaga kerja tersedia }\end{array}$ & $\begin{array}{l}\text { Kelemahan }(\mathrm{W}) \\
\text { Sistem teknologi tradisional } \\
\text { Pakan belum efektif } \\
\text { SDM kurang berkualitas } \\
\text { Fungsi kelompok belum } \\
\text { berjalan baik }\end{array}$ \\
\hline $\begin{array}{l}\text { Peluang }(\mathbf{0}) \\
\text { Pasar tersedia } \\
\text { Dukungan pemerintah } \\
\text { ada } \\
\text { Layanan pendukung } \\
\text { tersedia }\end{array}$ & $\begin{array}{l}\text { Strategi SO } \\
\text { Meningkatkan produksi } \\
\text { dengan memanfaatkan lahan } \\
\text { yang berpotensi } \\
\text { Memberdayakan tenaga kerja } \\
\text { dengan bantuan dari } \\
\text { dukungan pemerintah } \\
\text { Memberikan teknologi baru } \\
\text { bagi pembudidaya }\end{array}$ & $\begin{array}{l}\text { Strategi WO } \\
\text { Meningkatkan SPK mengenai } \\
\text { cara pemberian pakan } \\
\text { menggunakan pakan alternatif } \\
\text { Melakukan pendampingan } \\
\text { mengenai peran dan fungsi } \\
\text { kelompok } \\
\text { Melakukan pendampingan } \\
\text { perhitungan analisa usaha }\end{array}$ \\
\hline $\begin{array}{l}\text { Ancaman (T) } \\
\text { Fluktuasi cuaca } \\
\text { Harga tidak stabil } \\
\text { Harga pakan mahal }\end{array}$ & $\begin{array}{l}\text { Strategi ST } \\
\text { Meningkatkan kualitas air } \\
\text { dengan cara penggunaan } \\
\text { probiotik pada air } \\
\text { Meningkatkan pengetahuan } \\
\text { mengenai analisa usaha untuk } \\
\text { menghindari ketidak stabilan } \\
\text { harga ikan. } \\
\text { Menggunakan pakan alternatif }\end{array}$ & $\begin{array}{l}\text { Strategi WT } \\
\text { Meningkatkan pengetahuan } \\
\text { CBIB untuk produksi yang } \\
\text { berkualitas } \\
\text { Pemanfaatan sumber daya } \\
\text { alam yang berkelanjutan dan } \\
\text { terpadu } \\
\text { meningkatkan fungsi } \\
\text { kelompok dengan baik }\end{array}$ \\
\hline
\end{tabular}

bahwa ketenagaan paling sedikit 3 (tiga) penyuluh perikanan Pegawai Negeri Sipil (PNS) di setiap potensi perikanan dan menumbuhkan I (satu) orang penyuluh perikanan swadaya pada setiap kelompok pelau utama. $\mathrm{Hal}$ ini menyebabkan terhambatnya kegiatan penyuluhan karena terbatasnya tenaga penyuluh yang memegang 3 kecamatan yaitu Kecamatan Caringin, Cicurug dan Kadudampit sebagai wilayah kerjanya.

Sarana kegiatan penyuluh penyuluh perikanan di Kecamatan Caringin berupa motor pengadaannya dipenuhi pada anggaran tahun 2012, meja kursi penyuluh yang berada di kantor Kecamatan, kertas HVS, buku agenda dan sebuah alat tulis diterimakan setiap tahun. Untuk pembiayaan penyuluh perikanan yang ada di Kecamatan Caringin mendapatkan dana APBN dan APBD karena merupakan penyuluh PNS. Sehingga dana yang didapat dari BOP sebesar Rp.960.000.triwulan ${ }^{-1}$, dan untuk penyuluh perikanan bantu sebesar Rp.350.000.triwulan ${ }^{-1}$. 
Tabel 11. Penilaian fungsi kelompok

\begin{tabular}{|c|c|c|c|c|c|c|c|c|c|}
\hline No & $\begin{array}{l}\text { Fungsi } \\
\text { Kelompok }\end{array}$ & 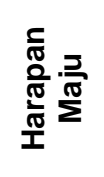 & 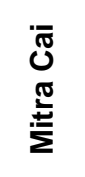 & 逽 & 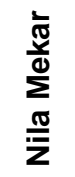 & 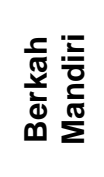 & 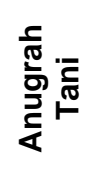 & 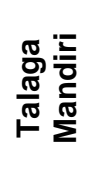 & $\begin{array}{l}\text { Rata- } \\
\text { Rata }\end{array}$ \\
\hline 1 & $\begin{array}{l}\text { Wahana } \\
\text { Belajar }\end{array}$ & 2 & 2,3 & 2 & 1,3 & 2 & 1,3 & 2 & 1,8 \\
\hline 2 & $\begin{array}{l}\text { Wahana } \\
\text { Kerjasama }\end{array}$ & 2 & 2,75 & 2,25 & 2,5 & 2 & 1 & 2 & 2 \\
\hline 3 & Unit Produksi & 3 & 3 & 2,6 & 2,6 & 2,6 & 3,6 & 3 & 2,9 \\
\hline 4 & $\begin{array}{l}\text { Unit Usaha } \\
\text { Atau Bisnis }\end{array}$ & 3,1 & 3,1 & 2,5 & 2,1 & 2,3 & 2,3 & 2,1 & 2,5 \\
\hline 5 & $\begin{array}{l}\text { Kesatuan } \\
\text { Swadaya Dan } \\
\text { Swadana }\end{array}$ & 2,8 & 3 & 3 & 2,6 & 2,6 & 2,6 & 2,6 & 2,7 \\
\hline 6 & $\begin{array}{l}\text { Penyedia } \\
\text { Sarana Dan } \\
\text { Prasarana } \\
\text { Produksi }\end{array}$ & 3 & 3 & 3 & 3 & 3 & 3,5 & 3 & 3 \\
\hline 7 & $\begin{array}{l}\text { Pengolahan } \\
\text { Dan } \\
\text { Pemasaran }\end{array}$ & 2,3 & 2,3 & 2,6 & 2,3 & 2,3 & 2,6 & 2,6 & 2,4 \\
\hline 8 & $\begin{array}{l}\text { Unit Jasa } \\
\text { Penunjang }\end{array}$ & 2 & 2 & 2 & 2,5 & 2 & 2,5 & 2 & 2,1 \\
\hline
\end{tabular}

Sumber :Data Primer Hasil Olahan 2018

Kriteria Penilaian (Sugiyono 2012)

$1-1,7=$ Kurang

$1,8-2,5=$ Cukup

$2,6-3,3=$ Baik

$3,4-4,0=$ Sangat Baik

Kegiatan penyuluhan rutin Caringin dengan metoda pertemuan dilaksanakan secara swadaya dan kelompok dan anjang sana. Sasaran swadana. Penyelenggaran penyuluh di Kecamatan Caringin diawali dengan penyuluhan perikanan di Kecamatan pembuatan rencana kerja penyuluh. Caringin adalah kelompok pembudidaya Penyuluhan dilakukan dengan melalui pendekatan komunikasi antara sasaran dan penyuluh yang didasari pada prinsip saling menghargai (Arikunto, 2010). Metoda penyuluhan yang dilakukan oleh penyuluh perikanan di Kecamatan ikan yang tersebar di beberapa desa. Kelompok pembudidaya ikan di Kecamatan Caringin saat ini hanya ada 9 Kelompok pembudidaya namun hanya 7 kelompok yang masih aktif.

Dari tabel diatas telah didapatkan nilai rata rata fungsi kelompok menurut 
UU No. 16 Tahun 2006 tentang SP3K, dari 8 fungsi kelompok tersebut 3 fungsi diantaranya telah memiliki kriteria baik dalam kisaran nilai 2,6 -3,3 yaitu sebagai unit produksi, kesatuan swadaya dan swadana dan sebagai unit penyedia sarana dan prasarana produksi. Namun 5 fungsi lainnya masih memiliki kriteria cukup dengan kisaran nilai 1,8 hingga 2,5 yaitu fungsi sebagai wahana belajar, sebagai wahana kerjasama, unit usaha dan bisnis, unit pengolahan dan pemasaran dan unit jasa penunjang. Dengan demikian perlu adanya peningkatan fungsi kelompok untuk meningkatkan kinerja kelompok perikanan di Kecamatan Caringin. Karena menurut Mustakini, (2010) Peningkatan fungsi kelompok mampu mengembangkan dinamika kelompok.

\section{Rencana Aksi Penyuluhan}

- Meningkatkan SPK mengenai cara pemberian pakan menggunakan pakan alternatif

- Melakukan pendampingan mengenai peran dan fungsi kelompok

- Melakukan pendampingan perhitungan analisa usaha

\section{SIMPULAN DAN SARAN}

Berdasarkan hasil analisis data secara primer maupun sekunder serta identifikasi permasalahan saat kegiatan penelitian maka dapat disimpulkan kondisi wilayah potensial perikanan di Kecamatan Caringin yaitu:

1. Berdasarkan identifikasi potensi wilayah di Kabupaten Sukabumi, Kecamatan Caringin memiliki luas wilayah seluas $3.542,362$ Hektar yang terdiri dari 9 desa dengan jumlah penduduk 48.578 jiwa. Potensi perikanan yang ada di Kecamatan Caringin yaitu bidang budidaya khususnya pembenihan dengan komoditas nila, lele dan koi. Pembenihan ikan nila dan lele menjadi komoditas unggulan di Kecamatan Caringin.

2. Sistem produksi budidaya di Kecamatan Caringin dilakukan secara tradisional, terlihat dari alat-alat dan kolam yang digunakan pembudidaya pada saat melakukan proses produksi.

3. Secara umum usaha perikanan yang dilakukan di Kecamatan Caringin menguntungkan. Hal tersebut terlihat dari analisa usaha responden di wilayah tersebut.

4. Sistem penyuluhan perikanan di Kecamatan Caringin belum sepenuhnya sesuai dengan idealnya sebuah sistem penyuluhan, terkait dengan 
jumlah personal dan sarana prasarana yang ada.

5. Permasalahan yang ditemukan di Kecamatan Caringin yaitu pakan buatan yang mahal, maka pembudidaya menggunakan pupuk organic sebagi pakan.

Hal-hal yang dapat disarankan kepada pihak terkait yang berkaitan dengan pelaksanaan penelitian adalah:

1. Perlu adanya evaluasi sistem penyuluhan perikanan di Kecamatan Caringin, terkait dengan perkembangan pelaku perikanannya. Yang dimaksud adalah penambahahan atau pengaturan personal juga sarana dan prasarana.

2. Perlu pembaharuan teknologi tradisional menjadi semi intensif bahkan intensif karena dalam pelaksanaan usaha budidaya ikan nila pada kelompok perikanan di Kecamatan Caringin selama ini masih bersifat alami atsau tradisional.

\section{DAFTAR PUSTAKA}

Arikunto, S., 2010. Prosedur Penelitian Suatu Pendekatan Praktik. Rineka Cipta, Jakarta (ID).

BPS, 2017. Kecamatan Caringin Dalam Angka 2017. Badan Pusat Statistik Sukabumi, Sukabumi (ID).
Firdaus, M., 2011. Ekonometrika Suatu Pendekatan Aplikatif Edisi Kedua. Bumi Aksara Jakarta.

Khairuman, Amri, K., 2003. Budidaya Ikan Nila Secara Intensif. Agromedia Pustaka, Depok (ID).

Laksana, F., 2008. Manajemen pemasaran pendekatan praktis. Yogyakarta Graha IImu.

Mahyuddin, K., 2010. Panduan Lengkap Agribisnis Lele. Penebar Swadaya, Jakarta (ID).

Murachman, N.H., Soemarno, M.S., 2010. 2010. Model Polikultur Udang Windu (Penaeus monodon Fab), Ikan Bandeng (Chanoschanos Forskal) dan Rumput Laut (Gracillaria sp.) Secara Tradisional. J. Pembang. dan Alam Lestari 1, 1-10.

Mursyid, M., 2009. Manajemen Pemasaran. PT Bumi Aksara, Jakarta (ID).

Mustakini, J.H., 2010. Analisis dan Desain Sistem Informasi, Edisi III. Yogyakarta Andi Offset.

Nisak, Z., 2013. Analisis SWOT untuk menentukan strategi kompetitif. J. Ekbis 9, 468-476.

Rangkuti, F., 2008. Analisis SWOT Teknik Membedah Kasus Bisnis. Reorientasi Konsep Perencanaan Strategis Untuk Menghadapi Abad 21. 
Samsuni, S., 2017. Manajemen sumber daya manusia. Al-Falah J. IIm. Keislam. dan Kemasyarakatan 17, 113-124.

Sugiyono, 2015. Metode Penelitian Bisnis. Alfabeta, Bandung (ID).

Sugiyono, 2012. Metode Penelitian

Kuantitatif, Kualitatif dan $R$ \& $D$. Alfabeta, Bandung (ID).

Suliyanto, 2011. Studi Kelayakan Bisnis.

Andi Publisher, Jakarta (ID). 
